\title{
Antibiotics in fetal and early life and subsequent childhood asthma: nationwide population based study with sibling analysis
}

\author{
(C) $(1)(9)$ OPEN ACCESS
}

\author{
Anne K Örtqvist doctoral candidate ${ }^{1}$, Cecilia Lundholm statistician ${ }^{1}$, Helle Kieler associate professor ${ }^{2}$, \\ Jonas F Ludvigsson professor ${ }^{13}$, Tove Fall associate professor ${ }^{4}$, Weimin Ye professor ${ }^{1}$, Catarina \\ Almqvist professor ${ }^{15}$
}

\begin{abstract}
'Department of Medical Epidemiology and Biostatistics, Karolinska Institutet, PO Box 281, 17177 Stockholm, Sweden; ${ }^{2}$ Centre for Pharmacoepidemiology T2, Department of Medicine, Karolinska University Hospital, 17176 Stockholm, Sweden; ${ }^{3}$ Department of Paediatrics, Örebro University Hospital, 70185 Örebro, Sweden; ${ }^{4}$ Department of Medical Sciences, Molecular Epidemiology and Science for Life Laboratory, Uppsala University, Dag Hammarskjöldsväg 14B, Uppsala Science Park, Uppsala, Sweden; ${ }^{5}$ Astrid Lindgren Children's Hospital, Lung and Allergy Unit, Karolinska University Hospital, 17176 Stockholm, Sweden
\end{abstract}

\begin{abstract}
Objective To investigate the association between exposure to antibiotics in fetal and early life and asthma in childhood, with adjustment for confounding factors.

Design Nationwide prospective population based cohort study, including sibling control design.

Setting Swedish population identified from national demographic and health registers.

Participants 493785 children born 2006-10; 180894 of these were eligible for sibling analyses.

Main outcome measure Asthma defined as having both an asthma diagnosis and dispensed asthma drugs. The association between antibiotic exposure and asthma was investigated in the whole cohort with Cox proportional hazard regression. A stratified proportional hazards model conditional on sibling group was used to adjust for shared factors within families. Confounding by respiratory infections was assessed by investigating whether specific groups of antibiotics were associated with asthma.
\end{abstract}

Results Antibiotic exposure in fetal life was associated with an increased risk of asthma in cohort analyses (hazard ratio 1.28 , 95\% confidence interval 1.25 to 1.32 ), but not in sibling analyses $(0.99,0.92$ to 1.07$)$. In cohort analyses, antibiotics used to treat respiratory infections in childhood were associated with a more pronounced increased risk of asthma (4.12, 3.78 to 4.50$)$ than antibiotics used for urinary tract and skin infections $(1.54,1.24$ to 1.92$)$. In sibling analyses, the excess risks after exposure to antibiotics for respiratory infections decreased (2.36,
1.78 to 3.13 ) and disappeared for antibiotics for urinary tract and skin $(0.85,0.47$ to 1.55$)$.

Conclusions Previous positive associations between exposure to antibiotics in fetal and early life and subsequent childhood asthma could have been caused by confounding by shared familial factors, in addition to confounding by respiratory infections.

\section{Introduction}

The increasing use of antibiotics has coincided with a rise in childhood asthma. ${ }^{12}$ This has triggered a surge of observational studies investigating the potential harmful role of exposure to antibiotics in fetal life $\mathrm{e}^{3-7}$ and childhood ${ }^{6-20}$ on subsequent development of wheeze and asthma. Earlier results, however, are conflicting, possibly because of different selection of populations, study designs, and potential bias. Previous studies that have found positive associations between antibiotic exposure in fetal life and childhood asthma have hypothesised that treatment of the mother with antibiotics during pregnancy could trigger a disease process in perinatal life in susceptible individuals. ${ }^{3-5}$ Some studies have also suggested that a causal association between antibiotic exposure in childhood and asthma is plausible $e^{8-10}$ and, in line with the microflora hypothesis, that exposure to antibiotics could lead to an increased incidence of allergic disease such as asthma. ${ }^{21}$

Systematic reviews have highlighted that the associations between antibiotic exposure and asthma could be caused by bias. ${ }^{22}$ Confounding by indication implies that the association 
is confounded by a third factor (such as respiratory infections) that could be the indication for antibiotic use and a risk factor for asthma, ${ }^{24}$ whereas reverse causation indicates that first occurrences of symptoms of asthma (associated with respiratory infections) have been treated with antibiotics, thereby inducing an association between antibiotics and asthma. Lack of adjustment for residual familial factors-for example, genetic and environmental confounding factors shared within families such as a genetic predisposition to respiratory infections and asthma, consultation patterns or other lifestyle and home environmental factors-is another potential source for bias. ${ }^{17} 25$ Some studies have suggested that the association between antibiotics and asthma might be confounded by indication or reverse causation ${ }^{11-14} 1617$ or consultation patterns. ${ }^{315}{ }^{18}$ To date, however, no study has investigated the association between exposure to antibiotics measured from the start of pregnancy and childhood asthma, taking familial factors into account.

Sibling studies provide the opportunity to study the association between antibiotics and asthma, with adjustment for familial factors. ${ }^{25}$ Full siblings share half of their genes, some intrauterine exposures, and parental factors and can be discordant regarding exposure to antibiotics. If associations seen in a cohort of siblings remain when non-affected siblings are used as controls for the affected children, then factors specific to each individual (such as the indication for antibiotic treatment) are assumed to be involved in the underlying causal pathways. On the contrary, if the association disappears or is diluted, it indicates that factors common to the siblings (such as parental factors) are involved.

We examined the association between exposure to antibiotics in fetal life or childhood and subsequent development of asthma by examining a prospective nationwide cohort of children followed from start of their mother's pregnancy up to school age. By exploring the association within families using sibling controls, we adjusted for familial factors, thereby further assessing causality. We studied the possibility of confounding by indication and reverse causation from respiratory infections by investigating whether specific groups of antibiotics (as a proxy for the indication of the treatment) were associated with asthma.

\section{Method}

\section{Study population and design}

This nationwide population based register study included Swedish children born to women who were pregnant between July 2005 and December 2010, identified from the Medical Birth Register. The cohort was linked to the Multi-Generation Register with the Swedish personal identity number to identify parents and siblings. The personal identity number enables unambiguous linkage between the registers held by the Swedish National Board of Health and Welfare and Statistics Sweden.

\section{Variables}

We collected information on exposure and outcome from the Swedish Prescribed Drug Register, which contains complete data on dispensed drugs since July 2005, and the National Patient Register with complete nationwide information on all inpatient diagnoses since 1987 and specialist outpatient diagnoses since 2001 .

\section{Exposure}

Information on generic names and dates of filled prescriptions of systemic antibiotics (Anatomical Therapeutic Chemical (ATC) classifications system code J01A-J01X) was retrieved from the Swedish Prescribed Drug Register from July 2005 to the end of follow-up. All antibiotics were divided into three groups, modified from Marra and colleagues ${ }^{10}$ and as described elsewhere ${ }^{613}$ : "any antibiotics" included any type of antibiotics; "airway antibiotics" included antibiotics used to treat respiratory infections (amoxicillin, penicillin, cephalosporin, and macrolides), and "urinary tract or skin and soft tissue antibiotics" (pivmecillinam, trimethoprim, sulphonamide, ciprofloxacin, norfloxacin, nitrofurantoin, cloxacillin, flucloxacillin, and dicloxacillin).

\section{Outcome}

Children were classed as having asthma if they had a diagnosis of asthma (ICD-10 (international classification of diseases, 10th revision) J45) registered in the National Patient Register and fulfilled one or both of two criteria for asthma drugs (ATC: R03) from the Swedish Prescribed Drug Register: two or more dispensed inhaled corticosteroids, leukotriene receptor antagonists, or fixed combinations of $\beta 2$ agonists and corticosteroids, with gaps of two or more weeks between distributions or three or more dispensed asthma drugs as previously mentioned or short acting $\beta 2$ agonists within a year. ${ }^{26}$ Date of onset was set as the date of prescription of any of the drugs or date of diagnosis, whichever came first.

\section{Other variables}

We collected information on child's birth year, sex, birth weight (grams), gestational age (days), mode of delivery (vaginal, instrumental, emergency, or elective caesarean section), maternal smoking at first visit to the antenatal care clinic (yes/no), respiratory diagnosis as newborn (ICD-10: P22-P28), maternal age at delivery, parity (child's birth order), family situation (mother cohabits with child's father, or other), mother's country of birth (Sweden, other Nordic countries, or other) from the Medical Birth Register, which includes data on more than $98 \%$ of all births in Sweden. The highest level of education of either parent $(0-9,10-12,>12$ years) was retrieved from the Longitudinal integration database for health insurance and labour market studies. Maternal asthma was defined as the mother having either fulfilled the criteria of dispensed asthma drugs or a diagnosis of asthma during the study period.

Start date of pregnancy was estimated as the date of birth minus gestational age in days. Duration of pregnancy was further divided into three trimesters (first: 1-91 days; second: 92-189 days; third: $\geq 190$ days). To ensure full coverage of exposure to antibiotics during fetal life and childhood from the Swedish Prescribed Drug Register, we restricted the cohort to children from pregnancies with an estimated start date of pregnancy as on or after 1 July 2005. Information on date of migration and death was collected from the Total Population Register. We excluded 9631 children born to women who migrated to Sweden during the pregnancy.

\section{Statistical analysis}

The analyses were performed in two steps. Firstly, we analysed the association between antibiotic exposure and asthma in the whole cohort of children using Cox proportional hazard regression, with attained age as analysis time scale and sandwich estimator of standard errors to account for clustering within sibling groups. Follow-up was censored at study outcome, emigration, death, or end of study period (31 December 2011), whichever occurred first. Exposure to antibiotics in childhood was included in the model as a time (age) varying exposure. The proportional hazards assumption was tested with 
Schoenfeld's residuals. Non-proportional hazards were found for childhood exposure to antibiotics. Consequently, we allowed for time varying effects.

Secondly, we used a sibling control design to adjust for familial factors. For the controls we used all full siblings (excluding 9896 children for whom the father's identity was unknown) who did not have the outcome of interest yet and who were still in the study at the at which the index child developed asthma. While all siblings with discordant outcomes contribute to the hazard ratio estimates of the covariates, only siblings who are also discordant on exposure are informative for the estimation of the hazard ratios for the exposure. Thus, for tabulated frequencies in the sibling control analyses we report the number of families with siblings discordant on both outcome and exposure. There were one to four controls per case and cases without eligible sibling controls were excluded. We used a stratified Cox proportional hazard model conditional on sibling group to analyse the sibling control design data.

Results are reported both as crude and adjusted for maternal smoking during pregnancy, parity, family situation (cohort and sibling analyses), mother's country of birth, parental education, and maternal asthma (only cohort) for the analyses of antibiotic exposure in fetal life. Analyses of exposure to antibiotics in childhood were adjusted for child's sex, birth weight, gestational age, mode of delivery, respiratory diagnosis as newborn, maternal age at delivery, parity, family situation, maternal antibiotic exposure in fetal life (cohort and sibling analyses), and mother's country of birth, parental education (only cohort) and for interaction between age and parity (only sibling analyses).

We performed subanalyses to explore the association of exposure during first, second, and third trimester of the pregnancy and asthma, and between exposure to antibiotics in the first year of life and incident asthma from the age of 2 .

A Poisson regression model, with restricted cubic splines (six knots) for time since first antibiotic exposure, was fitted to further assess potential reverse causation.

\section{Sensitivity analyses}

The Swedish Prescribed Drug Register reports only on antibiotics dispensed outside hospitals and most of antibiotics in Sweden $(90 \%)$ are captured in the register. ${ }^{27}$ In a sensitivity analysis, however, we included in the group "any antibiotics" those children who had been admitted to hospital and given a diagnosis previously shown to have a high correlation with antibiotic treatment. ${ }^{28}$ The effect of antibiotic exposure on asthma in the full cohort was further investigated by inclusion of interaction terms between birth order (first born compared with not first born) and antibiotic exposure. The association between antibiotics in childhood and asthma was further tested for a dose-response relation between number of prescriptions $(0,1,2-3$, or $\geq 4$ as a continuous variable) and asthma. All analyses of exposure to antibiotics in fetal life and childhood and subsequent asthma were also analysed with asthma drug and diagnosis separately and further restricted to mothers born in Sweden.

All analyses were performed with Stata statistical software, version 13.

\section{Results}

Figure 1 shows the final study populations for the cohort and sibling control analyses $\Downarrow$. We included 493785 children in the cohort analyses, and 180894 were eligible for the sibling control analyses. During the study period 4922 children emigrated and 1448 died. Tables 1 and 2 show the prevalence of asthma by cohort characteristics for the full cohort and for the sibling cohort $\downarrow \Downarrow$. Overall, $6 \%$ of the children in the cohorts were defined as having asthma. In total, $20 \%$ of the children in the full cohort and $16 \%$ of the children in the sibling cohort had been exposed to antibiotics in fetal life, and at least one prescription of any antibiotic during childhood was filled for $62 \%$ of children in both cohorts. An additional $4 \%$ of children in both cohorts were assumed to have been exposed to antibiotics in hospital.

\section{Antibiotics in fetal life}

Table 3 shows the crude and adjusted hazard ratios and $95 \%$ confidence intervals for the association between antibiotics in fetal life and childhood asthma in the cohort and sibling control analyses $\Downarrow$. The crude cohort analyses showed that any antibiotics in fetal life was significantly associated with a $36 \%$ increased risk of asthma in childhood. There was a comparable increased risk for airway antibiotics (hazard ratio $1.41,95 \%$ confidence interval 1.37 to 1.46 ). The excess risk associated with urinary tract/skin antibiotics was somewhat lower, but still significantly associated with asthma $(1.25,1.20$ to 1.30$)$. After adjustment for confounding variables, antibiotic exposure in fetal life remained significantly associated with asthma but reduced for any and airway antibiotics. In the sibling control analyses, the association disappeared; the adjusted hazard ratio was $0.98(0.90$ to 1.07$)$ for airway antibiotics and 0.98 (0.88 to 1.10$)$ for urinary tract/skin antibiotics. We found no difference in the hazard ratios (cohort and sibling control analyses) between trimesters for any group of antibiotics.

\section{Antibiotics during childhood}

Tables 4 and 5 show the crude and adjusted hazard ratios and 95\% confidence interval for asthma in relation to any antibiotics in different age bands in the full cohort and sibling control analyses $\Downarrow \Downarrow$. The highest risk was found among the youngest children (adjusted hazard ratio 3.71, 95\% confidence interval 3.41 to 4.03 ), and risk decreased with age (table 4 ). In the sibling control analyses all estimates were clearly lower than in the cohort analyses $(2.11,1.61$ to 2.76 , in the youngest children) (table 5). We found similar estimates in sensitivity analyses including children with presumed antibiotic exposure in hospitals in the group any antibiotics.

Table 6 and 7 show the associations between airway and urinary tract/skin antibiotics and subsequent asthma $\downarrow \Downarrow$. For both groups of antibiotics, the cohort analyses showed a decreased hazard ratio with increasing age, but the difference in risk was more pronounced after exposure to airway antibiotics (adjusted hazard ratio $4.12,95 \%$ confidence interval 3.78 to 4.50 ) compared with urinary tract/skin antibiotics $(1.54,1.24$ to 1.92$)$ in the youngest children (table $6 \Downarrow$ ). In the sibling control analyses, the estimates were clearly decreased compared with the cohort analyses, where the association with airway antibiotics remained significant $(2.36,1.78$ to 3.13$)$, and the association between urinary tract/skin antibiotics and asthma disappeared $(0.85,0.47$ to 1.55 ) (table $7 \Downarrow$ ).

Table 8 and 9 shows the associations between antibiotic exposure in first year of life and incidence of asthma from the age of $2 \Downarrow \Downarrow$. We found significant associations for all groups of antibiotics with asthma in the cohort analyses, but no associations remained in the sibling control analyses.

Figure 2 shows the hazard ratio for asthma in relation to time since first exposure to any, airway, and urinary tract/skin 
antibiotics in childhood $\Downarrow$. The hazard ratio for asthma in relation to any and airway antibiotics decreased steeply with time since exposure from about four to two during the first six months after antibiotic treatment. For urinary tract/skin antibiotics the hazard ratio slightly increased after exposure and then returned to the initial hazard ratio of around 1.25 in the years after exposure.

Sensitivity analyses showed that first born children had a higher excess risk of asthma than subsequent children after exposure to any and airway antibiotics before 1.5 years of age $(\mathrm{P}<0.001$ for interaction between birth order and exposure) but not after exposure to urinary tract/skin antibiotics $(\mathrm{P}=0.38)$. In the full cohort, we found a dose-response relation for the association between increasing number of prescriptions for all groups of antibiotics and asthma $(\mathrm{P}<0.001$, all age groups). In sibling analyses, the dose-response relation remained for any and airway antibiotics $(\mathrm{P}<0.001$, all age groups $)$, but not for urinary tract/skin antibiotics ( $\mathrm{P}=0.22-0.97$ for different age groups $)$. Analyses restricted to mothers born in Sweden produced similar estimates (data not tabulated). Analyses repeated with asthma drugs and diagnosis as separate outcomes yielded comparable estimates (tables A-C in appendix).

\section{Discussion}

Our results, based on a nationwide population based birth cohort, show a positive association between exposure to antibiotics in fetal life or childhood and subsequent asthma. In sibling control analyses, however, these associations disappeared or clearly decreased, indicating that the association might be strongly confounded by factors shared by families. To our knowledge, this is the first study to use sibling control analyses to assess the causality of the association between antibiotics and asthma. Our findings support the view that the association between fetal exposure to antibiotics and asthma is affected by confounding factors shared by siblings. We also found that the association between antibiotics for urinary tract/skin conditions in childhood and asthma disappeared in the sibling analyses. In analyses restricted to exposure during the first year of life and incident asthma from the age of 2, the association disappeared for all groups of antibiotics. This indicates that the association seen in the cohort is confounded both by familial factors and by indication or reverse causation.

\section{Previous studies}

Some previous studies have suggested that exposure to antibiotics in fetal life increases the risk of subsequent asthma and wheeze, ${ }^{3-5}$ whereas another study, with a fairly small study population, reported similar estimates but no significant associations. ${ }^{7}$ It has also been reported that the risk of transient early, persistent, and late onset wheezing differed by types of antibiotics, though exposure during pregnancy and wheezing outcomes were based on parental report and thus recall bias might have been a problem. ${ }^{4}$ In accordance with others we found similar risks of asthma regardless of trimester ${ }^{3}$ and groups of antibiotics, ${ }^{36}$ and the risk disappeared altogether in the sibling analyses.

Our results from the cohort analyses suggest that the excess risk of asthma after exposure to antibiotics in childhood decreases with increasing age. ${ }^{14}{ }^{17} 19$ In addition, the excess risk decreases with time since first exposure to any and airway antibiotics independent of age at first exposure. ${ }^{17}$ In line with the microflora hypothesis, ${ }^{21}$ which suggests that antibiotics can disrupt the normal microflora-mediated mechanisms of immunological tolerance in the mucosa leading to an increased risk of allergic immune responses, it could be hypothesised that the impact of antibiotics on the gut microflora and development of the immune system is strongest in the first year of life or shortly after exposure. $^{29}$

Alternatively, our cohort results could be explained by difficulties in differentiating early wheezing caused by respiratory infections from asthma or obstructive bronchitis in young children. ${ }^{16}$ Consequently, first time symptoms of asthma might be treated with antibiotics, thereby inducing an association between antibiotics and asthma (reverse causation). Alternately, antibiotics were given to treat respiratory infection, in itself a risk factor for asthma, resulting in confounding by indication. Adjustment for respiratory infections has previously led to decreased risk estimates or loss of statistical significance, further supporting these potential sources of bias. ${ }^{911}{ }^{14}{ }^{20}$ We could not adjust for respiratory infections because the Swedish Prescribed Drug Register does not provide indication for the actual prescriptions, nor were we able to adjust for number of doctor's visits as visits in primary care are not recorded in the National Patient Register. Yet, based on previous studies ${ }^{6}{ }^{13}$ and standardised treatment guidelines, we categorised antibiotics into those used to treat respiratory infections or not, and we confirm previous findings that airway antibiotics were associated with asthma, whereas urinary tract/skin antibiotics were not. ${ }^{13}$ Metsälä and colleagues recently found that the effect of urinary tract antibiotics on asthma, although not significant, was similar to the effect of airway antibiotics. ${ }^{6}$ Marra and colleagues found a significant risk of asthma independent of classes of antibiotics and an increasing risk with number of antibiotic courses administered. ${ }^{10}$ We also found an increased risk of asthma ${ }^{6}{ }^{10}$ and a dose-response relation between number of prescriptions and asthma ${ }^{10}$ for any type of antibiotics in the cohort analyses. In the sibling analyses independent of timing of exposure, however, the association and dose-response relation disappeared for urinary tract/skin antibiotics. Furthermore, in sibling analyses restricted to exposure in first year of life, the associations disappeared for all groups of antibiotics. The discrepancy between our studies could be caused by variances in antibiotic prescription practices between countries or by our approach of adjusting for shared factors within families.

Having older siblings has been suggested to protect younger children from developing asthma. ${ }^{30} \mathrm{We}$ found that firstborn children had a higher excess risk of asthma than subsequent children after exposure to any and airway antibiotics before the age of 1.5 years. There was no difference after exposure to urinary tract/skin antibiotics. These results support that the associations seen in the cohort, independent of birth order, are confounded by familial factors and by indication or reverse causation. In a study by Semic-Jusufagic and colleagues, the possibility of confounding by indication was further highlighted. ${ }^{17}$ The authors found that antibiotics given in early life were associated with an increased susceptibility to viral infections because of impaired antiviral immunity and also to genetic variants on chromosome $17 \mathrm{q} 21$ locus, which is strongly associated with asthma. ${ }^{31}$

In the sibling control analyses we were able to adjust for residual genetic and environmental confounding factors shared by families, such as a genetic predisposition to respiratory viral infections and asthma, consultation patterns, lifestyle, and home environmental factors. Thus, even though we confirmed previous positive associations between antibiotic exposure in fetal life and childhood and asthma in our cohort analyses, the associations disappeared or clearly decreased in sibling control analyses, indicating that previous studies as well as our own cohort results might be confounded by familial factors. The 
remaining effect of airway antibiotics is most likely caused by confounding by indication or reverse causation, which is not accounted for in the sibling analyses. This is further supported by the subanalyses restricted to children exposed in first year of life and incident asthma from age 2, in whom the association disappeared for all groups of antibiotics.

\section{Strengths and limitations}

The strength of our study is the large dataset in which full siblings have been identified, allowing for analyses taking shared (unmeasured) factors within families into account. Furthermore, with objectively and prospectively collected measures of exposure and validated outcomes ${ }^{26}$ from population based registers, precluding recall bias, we were able to assess the association between antibiotics and asthma over time. In addition to information on prescribed antibiotics, we were also able to include information on assumed exposure to antibiotics in hospital. Moreover, our population based design means our findings are generalisable.

The study has some limitations. Firstly, we were not able to take adherence to treatment ${ }^{32}$ or delayed prescribing ${ }^{33}$ into account. Yet, exposure to antibiotics was defined as a filled prescription for antibiotics, which reduces the risk that delayed prescribing affected our results. Secondly, we were not able to control for antibiotics prescribed abroad, which could be relevant for children of mothers born outside Sweden, who might spend longer periods abroad, potentially leading to associations driven towards the null. Sensitivity analyses restricted to children of women born in Sweden, however, produced similar results. Thirdly, even with our large study population, the number of families discordant for both urinary tract/skin antibiotics in childhood and asthma were fewer than in the analyses of fetal exposure, yielding broader confidence intervals.

\section{Conclusion and implications}

In conclusion, our study suggests that the association between antibiotics and asthma is caused by confounding factors shared within families, in addition to confounding by indication or reverse causation because of respiratory infections. As there is a considerable threat from antibiotic resistance worldwide, it is of great importance to acknowledge that though antibiotics might not cause asthma, careful consideration is required as to whether respiratory symptoms should be treated with them.

We thank Åsa Eck, who contributed with excellent data collection and management, Björn Wettermark for fruitful discussions, and Miriam Elfström for language proof reading.

Contributors: The study was initiated by WY and CA, and designed by AKÖ, CL, WY, and CA. AKÖ performed the statistical analysis and wrote the initial draft with supervision from CL and CA. JFL, HK, TF, and WY contributed with invaluable support for data analyses, interpretation of findings and critical revision of the article. WY and CA obtained the financial support. All authors had full access to data, reviewed and approved the final version of the article submitted for publication. AKÖ, $\mathrm{CL}$, and $\mathrm{CA}$ are guarantors.

Funding: This study was funded by the Swedish Research Council (grant No 2011-3060) through the Swedish Initiative for Research on Microdata in the Social and Medical Sciences (SIMSAM) framework grants No 80748301 and 340-2013-5867, grants provided by the Stockholm County Council (ALF project), the strategic research programme in epidemiology at Karolinska Institutet, and the Swedish Heart Lung Foundation. The funding sources had no role in the study design; the collection, analysis and interpretation of data; and the writing of the article and the decision to submit it for publication.
Competing interests: All authors have completed the ICMJE uniform disclosure form at www.icmje.org/coi_disclosure.pdf. and declare that HK has received institutional fees from RTI Health Solutions, Abbott, Abbvie, Astellas, Astra-Zeneca, Bayer, Janssen, Biotech, Janssen-Cilag, Lundbeck, MSD, Schering-Plough, and Pfizer for performing post-approval safety studies and comparative effectiveness studies outside the submitted work.

Ethical approval: The study was approved by the regional ethical review board in Stockholm, Sweden (DNR 2011/2012-31/5 and 2012/1179-32). Data sharing: No additional data available.

Transparency: The lead author affirms that this manuscript is an honest, accurate, and transparent account of the study being reported; that no important aspects of the study have been omitted; and that any discrepancies from the study as planned (and, if relevant, registered) have been explained.

1 Adriaenssens N, Coenen S, Versporten A, Muller A, Minalu G, Faes C, et al. European Surveillance of Antimicrobial Consumption (ESAC): outpatient antibiotic use in Europe (1997-2009). J Antimicrob Chemother 2011;66:3-12.

2 Asher MI, Montefort S, Bjorksten B, Lai CK, Strachan DP, Weiland SK, et al. Worldwide time trends in the prevalence of symptoms of asthma, allergic rhinoconjunctivitis, and eczema in childhood: ISAAC Phases One and Three repeat multicountry cross-sectional surveys. Lancet 2006;368:733-43.

3 McKeever TM, Lewis SA, Smith C, Hubbard R. The importance of prenatal exposures on the development of allergic disease: a birth cohort study using the West Midlands General Practice Database. Am J Respir Crit Care Med 2002;166:827-32.

4 Rusconi F, Galassi C, Forastiere F, Bellasio M, De Sario M, Ciccone G, et al. Maternal complications and procedures in pregnancy and at birth and wheezing phenotypes in children. Am J Respir Crit Care Med 2007;175:16-21.

5 Stensballe LG, Simonsen J, Jensen SM, Bonnelykke K, Bisgaard H. Use of antibiotics during pregnancy increases the risk of asthma in early childhood. J Pediatr 2013;162:832-8.

6 Metsälä J, Lundqvist A, Virta LJ, Kaila M, Gissler M, Virtanen SM. Prenatal and postnatal exposure to antibiotics and risk of asthma in childhood. Clin Exp Allergy 2014;doi:10.1111/ cea.12356.

7 Dom S, Droste JH, Sariachvili MA, Hagendorens MM, Oostveen E, Bridts $\mathrm{CH}$, et al. Preand post-natal exposure to antibiotics and the development of eczema, recurrent wheezing and atopic sensitization in children up to the age of 4 years. Clin Exp Allergy 2010;40:1378-87.

8 Goksor E, Alm B, Pettersson R, Mollborg P, Erdes L, Aberg N, et al. Early fish introduction and neonatal antibiotics affect the risk of asthma into school age. Pediatr Allergy Immunol 2013;24:339-44.

9 Kozyrskyj AL, Ernst P, Becker AB. Increased risk of childhood asthma from antibiotic use in early life. Chest 2007:131:1753-9.

10 Marra F, Marra CA, Richardson K, Lynd LD, Kozyrskyj A, Patrick DM, et al. Antibiotic use in children is associated with increased risk of asthma. Pediatrics 2009;123:1003-10.

11 Wickens K, Ingham T, Epton M, Pattemore P, Town I, Fishwick D, et al. The association of early life exposure to antibiotics and the development of asthma, eczema and atopy in a birth cohort: confounding or causality? Clin Exp Allergy 2008;38:1318-24.

12 Rusconi F, Gagliardi L, Galassi C, Forastiere F, Brunetti L, La Grutta S, et al. Paracetamol and antibiotics in childhood and subsequent development of wheezing/asthma: association or causation? Int J Epidemiol 2011;40:662-7.

13 Almqvist C, Wettermark B, Hedlin G, Ye W, Lundholm C. Antibiotics and asthma medication in a large register-based cohort study—confounding, cause and effect. Clin Exp Allergy 2012;42:104-11.

14 Celedon JC, Fuhlbrigge A, Rifas-Shiman S, Weiss ST, Finkelstein JA. Antibiotic use in the first year of life and asthma in early childhood. Clin Exp Allergy 2004;34:1011-6.

15 McKeever TM, Lewis SA, Smith C, Collins J, Heatlie H, Frischer M, et al. Early exposure to infections and antibiotics and the incidence of allergic disease: a birth cohort study with the West Midlands General Practice Research Database. J Allergy Clin Immunol 2002;109:43-50.

16 Marra F, Marra CA, Richardson K, Lynd LD, Fitzgerald MJ. Antibiotic consumption in children prior to diagnosis of asthma. BMC Pulm Med 2011;11:32.

17 Semic-Jusufagic A, Belgrave D, Pickles A, Telcian AG, Bakhsoliani E, Sykes A, et al. Assessing the association of early life antibiotic prescription with asthma exacerbations, impaired antiviral immunity, and genetic variants in 17q21: a population-based birth cohort study. Lancet Respir Med 2014;2:621-30.

18 Su Y, Rothers J, Stern DA, Halonen M, Wright AL. Relation of early antibiotic use to childhood asthma: confounding by indication? Clin Exp Allergy 2010:40:1222-9.

19 Ong MS, Umetsu DT, Mandl KD. Consequences of antibiotics and infections in infancy: bugs, drugs, and wheezing. Ann Allergy Asthma Immunol 2014;112:441-5.

20 Wang JY, Liu LF, Chen CY, Huang YW, Hsiung CA, Tsai HJ. Acetaminophen and/or antibiotic use in early life and the development of childhood allergic diseases. Int $J$ Epidemiol 2013;42:1087-99.

21 Noverr MC, Huffnagle GB. The 'microflora hypothesis' of allergic diseases. Clin Exp Allergy 2005;35:1511-20.

22 Murk W, Risnes KR, Bracken MB. Prenatal or early-life exposure to antibiotics and risk of childhood asthma: a systematic review. Pediatrics 2011;127:1125-38.

23 Heintze K, Petersen KU. The case of drug causation of childhood asthma: antibiotics and paracetamol. Eur J Clin Pharmacol 2013;69:1197-209.

24 Busse WW, Lemanske RF Jr, Gern JE. Role of viral respiratory infections in asthma and asthma exacerbations. Lancet 2010;376:826-34.

25 D'Onofrio BM, Lahey BB, Turkheimer E, Lichtenstein P. Critical need for family-based, quasi-experimental designs in integrating genetic and social science research. $\mathrm{Am} \mathrm{J}$ Public Health 2013;103:S46-55.

26 Örtqvist AK, Lundholm C, Wettermark B, Ludvigsson JF, Ye W, Almqvist C. Validation of asthma and eczema in population-based Swedish drug and patient registers. Pharmacoepidemiol Drug Saf 2013;22:850-60. 


\section{What is already known on this topic}

Numerous studies have reported conflicting results regarding the association between antibiotic exposure in fetal life and early childhood and subsequent development of asthma

Bias from confounding by indication and reverse causation from respiratory infections could explain previous positive associations

Lack of adjustment for residual genetic and environmental confounding factors shared by families is another potential source for bias, which has not been assessed to date

\section{What this study adds}

Cohort analyses showed an increased risk of asthma after antibiotic exposure in fetal life and childhood

The risk for asthma was stronger after childhood exposure to antibiotics used to treat respiratory infections than for those used for urinary tract and skin infections, implying confounding by indication or reverse causation

In the sibling analyses, the association between antibiotic exposure in fetal life and asthma disappeared, indicating that the association was affected by factors shared by siblings. For antibiotic exposure in childhood, the association disappeared for antibiotics used for urinary tract and skin infection and clearly decreased for antibiotics used for respiratory infections

Cohort results and previous findings have been confounded by genetic and environmental factors shared by families in addition to cofounding by indication or reverse causation of antimicrobials and occurrence of antimicrobial resistance in Sweden. 2012. www.sva. se/upload/Redesign2011/Pdf/Om_SVA/publikationer/Swedres_Svarm2012.pdf.

28 Almqvist C, Örtqvist AK, Gong T, Wallas A, Ahlén KM, Ye W, et al. Individual maternal and child exposure to antibiotics in hospital—a national population-based validation study. Acta Paediatrica (forthcoming).

29 Martin R, Nauta AJ, Ben Amor K, Knippels LM, Knol J, Garssen J. Early life: gut microbiota and immune development in infancy. Benef Microbes 2010;1:367-82.

30 Ball TM, Castro-Rodriguez JA, Griffith KA, Holberg CJ, Martinez FD, Wright AL. Siblings, day-care attendance, and the risk of asthma and wheezing during childhood. $N$ Engl J Med 2000;343:538-43.

31 Moffat MF, Kabesch M, Liang L, Dixon AL, Strachan D, Heath S, et al. Genetic variants regulating ORMDL3 expression contribute to the risk of childhood asthma. Nature 2007;448:470-3

32 Kardas P. Patient compliance with antibiotic treatment for respiratory tract infections. $J$ Antimicrob Chemother 2002:49:897-903.
33 Little P, Moore M, Kelly J, Williamson I, Leydon G, McDermott L, et al Delayed antibiotic prescribing strategies for respiratory tract infections in primary care: pragmatic, factorial, randomised controlled trial. BMJ 2014;348:g1606.

\section{Accepted: 30 October 2014}

\section{Cite this as: BMJ 2014;349:96979}

This is an Open Access article distributed in accordance with the Creative Commons Attribution Non Commercial (CC BY-NC 4.0) license, which permits others to distribute, remix, adapt, build upon this work non-commercially, and license their derivative works on different terms, provided the original work is properly cited and the use is non-commercial. See: http://creativecommons.org/licenses/by-nc/4.0/. 


\section{Tables}

Table 1/ Characteristics of children in full cohort and sibling cohort in analysis of association between fetal and childhood exposure to antibiotics and development of asthma

\begin{tabular}{|c|c|c|c|c|}
\hline & \multicolumn{2}{|c|}{ Full cohort } & \multicolumn{2}{|c|}{ Sibling cohort } \\
\hline & No of children & No (\%) with asthma & No of children & No (\%) with asthma \\
\hline Total No of children & 493785 & $29753(6.0)$ & 180894 & $11260(6.2)$ \\
\hline \multicolumn{5}{|l|}{ Birth year: } \\
\hline 2006 & 73865 & 5795 (7.9) & 30434 & 2241 (7.4) \\
\hline 2007 & 101323 & 7765 (7.7) & 36350 & $2603(7.2)$ \\
\hline 2008 & 103467 & $7278(7.0)$ & 36184 & 2495 (6.9) \\
\hline 2009 & 104967 & $5930(5.7)$ & 35553 & $2337(6.6)$ \\
\hline 2010 & 110163 & $2985(2.7)$ & 42373 & $1584(3.7)$ \\
\hline \multicolumn{5}{|l|}{ Sex: } \\
\hline Male & 254020 & $19093(7.5)$ & 93380 & 7377 (7.9) \\
\hline Female & 239765 & $10660(4.5)$ & 87514 & $3883(4.4)$ \\
\hline \multicolumn{5}{|l|}{ Birth weight $(\mathrm{g})$ : } \\
\hline$<2500$ & 21183 & $2374(11.2)$ & 10262 & $1134(11.1)$ \\
\hline 2500-2999 & 54499 & $3659(6.7)$ & 20940 & $1501(7.2)$ \\
\hline $3000-3499$ & 157486 & $9021(5.7)$ & 55717 & $3379(6.1)$ \\
\hline $3500-3999$ & 169582 & $9393(5.5)$ & 61023 & $3374(5.5)$ \\
\hline 4000-4499 & 72722 & $4113(5.7)$ & 26370 & $1470(5.6)$ \\
\hline$\geq 4500$ & 17600 & $1130(6.4)$ & 6314 & $386(6.1)$ \\
\hline Missing & 713 & $63(8.8)$ & 268 & $16(6.0)$ \\
\hline \multicolumn{5}{|c|}{ Gestational age at delivery (weeks): } \\
\hline$\leq 34$ & 12546 & $1771(14.1)$ & 6023 & $816(13.6)$ \\
\hline $35-36$ & 17356 & $1588(9.2)$ & 7634 & $709(9.3)$ \\
\hline $37-38$ & 96821 & $6903(7.1)$ & 36841 & $2685(7.3)$ \\
\hline $39-40$ & 248414 & $13546(5.5)$ & 90414 & $4975(5.5)$ \\
\hline$\geq 41$ & 118648 & $5945(5.0)$ & 39982 & $2075(5.2)$ \\
\hline \multicolumn{5}{|l|}{ Respiratory diagnosis at birth ${ }^{*}$} \\
\hline No & 480799 & $28382(5.9)$ & 175955 & $10706(6.1)$ \\
\hline Yes & 12986 & $1371(10.6)$ & 4939 & $554(11.2)$ \\
\hline \multicolumn{5}{|l|}{ Antibiotic exposure in fetal lifet: } \\
\hline Any antibiotics & 101135 & $7642(7.6)$ & 28939 & $2178(7.5)$ \\
\hline Airway antibiotics & 65213 & $5208(8.0)$ & 18971 & $1430(7.5)$ \\
\hline Urinary tract/skin antibiotics & 44525 & $3259(7.3)$ & 11668 & $900(7.7)$ \\
\hline \multicolumn{5}{|c|}{ Antibiotic exposure in childhoodł: } \\
\hline Any antibiotics & 305938 & $25306(8.3)$ & 112795 & $9414(8.4)$ \\
\hline Airway antibiotics & 292173 & $24859(8.5)$ & 107716 & $9232(8.6)$ \\
\hline Urinary tract/skin antibiotics & 64676 & $5922(9.2)$ & 23721 & $2132(9.0)$ \\
\hline $\begin{array}{l}\text { Antibiotics assumed from } \\
\text { hospital diagnosis§ }\end{array}$ & 21413 & $3438(16.1)$ & 7885 & $1246(15.8)$ \\
\hline
\end{tabular}

${ }^{*} \mathrm{ICD}$-10: respiratory distress of the newborn (P22), congenital pneumonia (P23), neonatal aspiration syndromes (P24), interstitial emphysema and related conditions originating in perinatal period (P25), pulmonary haemorrhage originating in perinatal period (P26), chronic respiratory disease originating in perinatal period (P27), and other respiratory conditions originating in perinatal period (P28).

†At least one antibiotic prescription to mothers during estimated duration of pregnancy.

$\ddagger$ At least one antibiotic prescription/hospital diagnosis associated with antibiotics in childhood.

§ICD-10: appendicitis (K35), sepsis (A40-A41), meningitis (A87, G00-G03), pneumonia (J18), skin infection (L08), cystitis (N30), and pyelonephritis (N10). 
Table 2| Maternal characteristics in full cohort and sibling cohort in analysis of association between fetal and childhood exposure to antibiotics and development of asthma

\begin{tabular}{|c|c|c|c|c|}
\hline & \multicolumn{2}{|c|}{ Full cohort } & \multicolumn{2}{|c|}{ Sibling cohort } \\
\hline & No of children & No (\%) with asthma & No of children & No (\%) with asthma \\
\hline Total No of children & 493785 & $29753(6.0)$ & 180894 & $11260(6.2)$ \\
\hline \multicolumn{5}{|l|}{ Mode of delivery: } \\
\hline Vaginal & 366662 & $20712(5.7)$ & 136452 & $7870(5.8)$ \\
\hline Instrumental & 38333 & $2235(5.8)$ & 12746 & $814(6.4)$ \\
\hline Elective caesarean section & 37934 & $2911(7.7)$ & 17893 & $1054(7.7)$ \\
\hline Emergency caesarean section & 50569 & $3880(7.7)$ & 13687 & $1518(8.5)$ \\
\hline Missing & 287 & $15(5.2)$ & 116 & $4(3.5)$ \\
\hline \multicolumn{5}{|l|}{ Smoking during pregnancy: } \\
\hline No & 439962 & $25516(5.8)$ & 162490 & $9806(6.0)$ \\
\hline Yes & 32743 & $2766(8.5)$ & 10184 & $877(8.6)$ \\
\hline Missing & 21080 & $1471(7.0)$ & 8220 & $577(7.0)$ \\
\hline \multicolumn{5}{|l|}{ Age at delivery (years): } \\
\hline$<19$ & 7746 & $462(6.0)$ & 1972 & $149(7.6)$ \\
\hline $19-24$ & 61960 & $3954(6.4)$ & 23118 & $1660(7.2)$ \\
\hline $25-29$ & 140790 & $8873(6.3)$ & 56079 & $3727(6.7)$ \\
\hline $30-34$ & 173923 & $10395(6.0)$ & 66494 & $3907(5.9)$ \\
\hline$\geq 35$ & 109366 & $6069(5.6)$ & 33231 & $1817(5.5)$ \\
\hline \multicolumn{5}{|l|}{ Parity (at current delivery): } \\
\hline 1 & 216643 & $11869(5.5)$ & 65781 & $4287(6.5)$ \\
\hline 2 & 181919 & $11805(6.5)$ & 80583 & $4767(5.9)$ \\
\hline 3 & 66979 & $4200(6.3)$ & 22647 & $1386(6.1)$ \\
\hline$\geq 4$ & 28244 & $1879(6.7)$ & 11883 & $820(6.9)$ \\
\hline \multicolumn{5}{|l|}{ Family situation: } \\
\hline Mother and father cohabit & 444030 & $26454(6.0)$ & 165892 & $10205(6.2)$ \\
\hline Mother lives alone, other & 27164 & $1761(6.5)$ & 6279 & $452(7.2)$ \\
\hline Missing & 22591 & $1538(6.8)$ & 8723 & $603(6.9)$ \\
\hline \multicolumn{5}{|l|}{ Country of birth: } \\
\hline Sweden & 393578 & $25007(6.4)$ & 148548 & $9562(6.4)$ \\
\hline Other Nordic countries & 7561 & $448(5.9)$ & 2649 & $174(6.6)$ \\
\hline Other & 92646 & $4298(4.6)$ & 29697 & $1524(5.1)$ \\
\hline \multicolumn{5}{|c|}{ Parents' highest level of education (years): } \\
\hline $0-9$ & 24141 & $1576(6.5)$ & 8023 & $557(6.9)$ \\
\hline $10-12$ & 180539 & $12239(6.8)$ & 62781 & $4305(6.9)$ \\
\hline$>12$ & 286922 & $15874(5.5)$ & 109666 & $6386(5.8)$ \\
\hline Missing & 2183 & $64(2.9)$ & 424 & $12(2.8)$ \\
\hline \multicolumn{5}{|l|}{ Maternal asthma: } \\
\hline No & 453278 & $24733(5.5)$ & 162887 & $9113(5.6)$ \\
\hline Yes & 40507 & $5020(12.4)$ & 18007 & $2147(11.9)$ \\
\hline
\end{tabular}


Table 3 | Hazard ratios (HR) and 95\% confidence intervals for asthma in relation to exposure to antibiotics in fetal life, overall and by trimester, in full cohort of children and for children with siblings

\begin{tabular}{|c|c|c|c|c|c|c|}
\hline \multirow[b]{2}{*}{$\begin{array}{l}\text { Groups of } \\
\text { antibiotics }\end{array}$} & \multicolumn{2}{|c|}{ All children* ${ }^{*}$} & \multicolumn{4}{|c|}{ Children with siblings } \\
\hline & Crude† HR (95\% Cl) & $\begin{array}{c}\text { Adjusted } \neq \S \text { HR }(95 \% \\
\text { Cl) }\end{array}$ & No of cases \{ & Crude HR $(95 \% \mathrm{Cl})$ & No of cases $\llbracket$ & $\begin{array}{c}\text { Adjusted§ HR (95\% } \\
\text { Cl) }\end{array}$ \\
\hline \multicolumn{7}{|l|}{ Any } \\
\hline Overall & $1.36(1.32$ to 1.39$)$ & 1.28 (1.25 to 1.32$)$ & 2799 & 1.00 (0.94 to 1.08$)$ & 2523 & 0.99 (0.92 to 1.07$)$ \\
\hline \multicolumn{7}{|l|}{ Trimester: } \\
\hline 1 & 1.35 (1.30 to 1.40$)$ & 1.29 (1.23 to 1.34$)$ & 1081 & $1.07(0.95$ to 1.20$)$ & 965 & 1.09 (0.97 to 1.23$)$ \\
\hline 2 & 1.39 (1.34 to 1.44$)$ & 1.30 (1.25 to 1.35$)$ & 1312 & $0.99(0.90$ to 1.10$)$ & 1171 & 0.97 (0.87 to 1.08$)$ \\
\hline 3 & 1.33 (1.28 to 1.39$)$ & 1.26 (1.21 to 1.31$)$ & 1913 & 0.95 (0.85 to 1.06$)$ & 1078 & 0.95 (0.84 to 1.06$)$ \\
\hline \multicolumn{7}{|l|}{ Airway } \\
\hline Overall & $1.41(1.37$ to 1.46$)$ & 1.31 (1.27 to 1.35$)$ & 1971 & 0.99 (0.91 to 1.07$)$ & 1773 & $0.98(0.90$ to 1.07$)$ \\
\hline \multicolumn{7}{|l|}{ Trimester: } \\
\hline 1 & 1.51 (1.43 to 1.58$)$ & $1.40(1.33$ to 1.47$)$ & 656 & 1.09 (0.94 to 1.26$)$ & 588 & $1.11(0.95$ to 1.30$)$ \\
\hline 2 & 1.45 (1.39 to 1.51$)$ & 1.33 (1.27 to 1.39$)$ & 863 & 0.97 (0.86 to 1.10$)$ & 768 & 0.97 (0.85 to 1.11$)$ \\
\hline 3 & $1.33(1.27$ to 1.39$)$ & 1.24 (1.18 to 1.30$)$ & 817 & 0.95 (0.83 to 1.09$)$ & 738 & $0.96(0.84$ to 1.11$)$ \\
\hline \multicolumn{7}{|c|}{ Urinary tract/skin } \\
\hline Overall & 1.25 (1.20 to 1.30$)$ & 1.23 (1.18 to 1.28$)$ & 1209 & $1.01(0.91$ to 1.12$)$ & 1087 & $0.98(0.88$ to 1.10$)$ \\
\hline \multicolumn{7}{|l|}{ Trimester: } \\
\hline 1 & 1.16 (1.09 to 1.23$)$ & 1.15 (1.08 to 1.22$)$ & 437 & $1.07(0.90$ to 1.28$)$ & 391 & 1.10 (0.91 to 1.33$)$ \\
\hline 2 & $1.30(1.23$ to 1.37$)$ & 1.26 (1.19 to 1.33$)$ & 544 & 0.99 (0.85 to 1.16$)$ & 485 & $0.93(0.78$ to 1.10$)$ \\
\hline 3 & 1.31 (1.24 to 1.39 ) & $1.28(1.21$ to 1.36$)$ & 460 & 0.94 (0.79 to 1.12$)$ & 415 & $0.92(0.76$ to 1.10$)$ \\
\hline
\end{tabular}

${ }^{\star}$ Excludes children born to mothers with prescriptions for antibiotics without license in Sweden during study period $(\mathrm{n}=9)$.

†23 900000 person years and 29745 events. Individuals with reported event before date of entry (birth) were excluded ( $n=8)$. $\ddagger 22600000$ person years and 28055 events.

$\S$ Adjusted for maternal smoking during pregnancy, parity, family situation (cohort and sibling analyses), and mother's country of birth, parental education, maternal asthma (cohort analyses), and age as analysis time scale. Individuals with missing information on included variables excluded.

IAll families discordant on asthma are included in analyses, but only those also discordant on exposure contribute to estimates in table therefore number of cases is number of families with siblings discordant for both antibiotic exposure and asthma. 
Table 4| Hazard ratios (HR) and $\mathbf{9 5 \%}$ confidence interval for asthma in relation to age at exposure to any antibiotics in childhood in full cohort of children

\begin{tabular}{|c|c|c|c|c|c|c|c|c|c|}
\hline \multirow[b]{2}{*}{$\begin{array}{l}\text { Age } \\
\text { (years) }\end{array}$} & \multicolumn{3}{|c|}{ Crude } & \multicolumn{3}{|c|}{ Adjusted * } & \multicolumn{3}{|c|}{ Adjusted† } \\
\hline & $\begin{array}{c}\text { Person } \\
\text { years }(1000)\end{array}$ & Events & HR $(95 \% \mathrm{Cl})$ & $\begin{array}{c}\text { Person } \\
\text { years }(1000)\end{array}$ & Events & HR $(95 \% \mathrm{Cl})$ & $\begin{array}{c}\text { Person } \\
\text { years }(1000)\end{array}$ & Events & HR $(95 \% \mathrm{Cl})$ \\
\hline $0-0.5$ & 245 & 4996 & $\begin{array}{c}3.97 \text { (3.66 to } \\
4.30)\end{array}$ & 233 & 4715 & $\begin{array}{c}3.71 \text { (3.41 to } \\
4.03)\end{array}$ & 233 & 4715 & $\begin{array}{c}3.78 \text { (3.48 to } \\
4.10)\end{array}$ \\
\hline $0.5-1$ & 241 & 8753 & $\begin{array}{c}2.74 \text { (2.61 to } \\
2.87)\end{array}$ & 229 & 8294 & $\begin{array}{c}2.59 \text { (2.47 to } \\
2.72)\end{array}$ & 229 & 8294 & $\begin{array}{c}2.61(2.49 \text { to } \\
2.74)\end{array}$ \\
\hline $1-1.5$ & 224 & 6486 & $\begin{array}{c}2.43(2.31 \text { to } \\
2.55)\end{array}$ & 213 & 6133 & $\begin{array}{c}2.31(2.20 \text { to } \\
2.43)\end{array}$ & 213 & 6133 & $\begin{array}{c}2.32(2.20 \text { to } \\
2.44)\end{array}$ \\
\hline $1.5-2$ & 194 & 4595 & $\begin{array}{c}2.17(2.04 \text { to } \\
2.31)\end{array}$ & 183 & 4337 & $\begin{array}{c}2.06(1.93 \text { to } \\
2.19)\end{array}$ & 183 & 4337 & $\begin{array}{c}2.06(1.93 \text { to } \\
2.20)\end{array}$ \\
\hline$\geq 2$ & 655 & 4915 & $\begin{array}{c}1.90(1.77 \text { to } \\
2.03)\end{array}$ & 612 & 4601 & $\begin{array}{c}1.80(1.68 \text { to } \\
1.93)\end{array}$ & 612 & 4601 & $\begin{array}{c}1.81 \text { (1.69 to } \\
1.94)\end{array}$ \\
\hline
\end{tabular}

*Adjusted for sex, birth weight, gestational age, mode of delivery, respiratory diagnoses as newborn, maternal age at delivery, parity, family situation, maternal antibiotic exposure in fetal life, mother's birth country, parental education, and age as analysis time scale. Individuals with reported event before date of entry (birth) were excluded ( $\mathrm{n}=312$ ). Individuals with missing information on included variables excluded.

†Additionally adjusted for antibiotic exposure defined from hospital diagnoses. 
Table 5| Hazard ratios (HR) and 95\% confidence interval for asthma in relation to age at exposure to any antibiotics in childhood in children with siblings

\begin{tabular}{|c|c|c|c|c|c|c|}
\hline \multirow[b]{2}{*}{ Age (years) } & \multicolumn{2}{|c|}{ Crude } & \multicolumn{2}{|c|}{ Adjusted* } & \multicolumn{2}{|c|}{ Adjusted $†$} \\
\hline & No of casesł & HR (95\% Cl) & No of casesł & HR (95\% Cl) & No of casesł & HR (95\% Cl) \\
\hline $0-0.5$ & 1109 & 1.89 (1.49 to 2.41$)$ & 993 & 2.11 (1.61 to 2.76 ) & 830 & 2.23 (1.71 to 2.91$)$ \\
\hline $0.5-1$ & 1704 & 1.51 (1.34 to 1.71$)$ & 1541 & 1.46 (1.28 to 1.67$)$ & 1337 & $1.47(1.29$ to 1.68$)$ \\
\hline $1-1.5$ & 955 & 1.77 (1.53 to 2.04$)$ & 859 & 1.82 (1.55 to 2.13 ) & 768 & 1.80 (1.53 to 2.11$)$ \\
\hline $1.5-2$ & 547 & $1.46(1.18$ to 1.80$)$ & 498 & $1.50(1.19$ to 1.89$)$ & 462 & $1.51(1.20$ to 1.91$)$ \\
\hline$\geq 2$ & 600 & $1.32(0.99$ to 1.76$)$ & 556 & $1.32(0.97$ to 1.79$)$ & 507 & $1.31(0.96$ to 1.78$)$ \\
\hline
\end{tabular}

*Adjusted for sex, birth weight, gestational age, mode of delivery, respiratory diagnoses as newborn, maternal age at delivery, parity, family situation, maternal antibiotic exposure in fetal life, age as analysis time scale, and parity included as interaction term with age. Individuals with missing information on included variables excluded.

†Additionally adjusted for antibiotic exposure defined from hospital diagnoses.

$\ddagger$ All families discordant on asthma are included in analyses, but only those also discordant on exposure contribute to estimates in table, therefore number of cases is number of families with siblings discordant for both antibiotic exposure and asthma. 
Table $6 \mid$ Hazard ratios (HR) and $95 \%$ confidence intervals for asthma in relation to age at exposure to airway and urinary tract/skin antibiotics in childhood in full cohort of children

\begin{tabular}{|c|c|c|c|c|}
\hline \multirow[b]{2}{*}{ Age (years) } & \multicolumn{2}{|c|}{ Airway antibiotics* } & \multicolumn{2}{|c|}{ Urinary tract/skin antibiotics ${ }^{*}$} \\
\hline & Crude HR (95\% Cl) & Adjusted† HR (95\% Cl) & Crude HR $(95 \% \mathrm{Cl})$ & Adjusted† HR (95\% Cl) \\
\hline $0-0.5$ & 4.46 (4.10 to 4.86$)$ & 4.12 (3.78 to 4.50$)$ & 1.64 (1.33 to 2.03$)$ & 1.54 (1.24 to 1.92$)$ \\
\hline $0.5-1$ & 2.83 (2.70 to 2.97$)$ & 2.65 (2.52 to 2.78$)$ & $1.60(1.43$ to 1.79$)$ & 1.54 (1.38 to 1.72$)$ \\
\hline $1-1.5$ & 2.49 (2.37 to 2.61$)$ & 2.34 (2.23 to 2.47$)$ & $1.41(1.27$ to 1.56$)$ & 1.37 (1.23 to 1.53$)$ \\
\hline $1.5-2$ & $2.20(2.07$ to 2.34$)$ & 2.07 (1.94 to 2.20$)$ & $1.22(1.09$ to 1.36$)$ & $1.19(1.07$ to 1.34$)$ \\
\hline$\geq 2$ & 1.91 (1.79 to 2.04$)$ & 1.79 (1.68 to 1.92$)$ & 1.21 (1.11 to 1.32$)$ & $1.20(1.10$ to 1.31$)$ \\
\hline
\end{tabular}

${ }^{*}$ Person time and number of events in cohort analyses of airway and urinary tract/skin antibiotics, same as for table 4 any antibiotics. Individuals with reported event before date of entry (birth) were excluded $(n=312)$.

†Adjusted for sex, birth weight, gestational age, mode of delivery, respiratory diagnoses as newborn, maternal age at delivery, parity, family situation, maternal exposure to antibiotics in fetal life, mother's country of birth, parental education, and age as analysis time scale. Individuals with missing information on included variables excluded. 
Table 7| Hazard ratios (HR) and 95\% confidence intervals for asthma in relation to age at exposure to airway and urinary tract/skin antibiotics in childhood for children with siblings

\begin{tabular}{|c|c|c|c|c|c|c|c|c|}
\hline \multirow{3}{*}{$\begin{array}{l}\text { Age } \\
\text { (years) }\end{array}$} & \multicolumn{4}{|c|}{ Airway antibiotics } & \multicolumn{4}{|c|}{ Urinary tract/skin antibiotics } \\
\hline & \multicolumn{2}{|c|}{ Crude } & \multicolumn{2}{|c|}{ Adjusted $^{\star}$} & \multicolumn{2}{|c|}{ Crude } & \multicolumn{2}{|c|}{ Adjusted $^{*}$} \\
\hline & Casest & HR (95\% Cl) & Casest & HR $(95 \%$ Cl) & Cases† & HR (95\% Cl) & Casest & HR $(95 \% \mathrm{Cl})$ \\
\hline $0-0.5$ & 1075 & $\begin{array}{c}2.16(1.68 \text { to } \\
2.79)\end{array}$ & 961 & $\begin{array}{c}2.36(1.78 \text { to } \\
3.13)\end{array}$ & 129 & $\begin{array}{c}0.70(0.41 \text { to } \\
1.20)\end{array}$ & 114 & $\begin{array}{c}0.85(0.47 \text { to } \\
1.55)\end{array}$ \\
\hline $0.5-1$ & 1655 & $\begin{array}{c}1.56(1.37 \text { to } \\
1.77)\end{array}$ & 1494 & $\begin{array}{c}1.51(1.31 \text { to } \\
1.73)\end{array}$ & 255 & $\begin{array}{c}0.93(0.71 \text { to } \\
1.21)\end{array}$ & 226 & $\begin{array}{c}0.94(0.70 \text { to } \\
1.25)\end{array}$ \\
\hline $1-1.5$ & 931 & $\begin{array}{c}1.85(1.59 \text { to } \\
2.14)\end{array}$ & 837 & $\begin{array}{c}1.91(1.62 \text { to } \\
2.24)\end{array}$ & 234 & $\begin{array}{c}0.98(0.73 \text { to } \\
1.30)\end{array}$ & 216 & $\begin{array}{c}0.98(0.72 \text { to } \\
1.33)\end{array}$ \\
\hline $1.5-2$ & 546 & $\begin{array}{c}1.50(1.21 \text { to } \\
1.86)\end{array}$ & 496 & $\begin{array}{c}1.54(1.22 \text { to } \\
1.95)\end{array}$ & 175 & $\begin{array}{c}1.02(0.71 \text { to } \\
1.45)\end{array}$ & 161 & $\begin{array}{c}0.98(0.66 \text { to } \\
1.44)\end{array}$ \\
\hline$\geq 2$ & 628 & $\begin{array}{c}1.38 \text { (1.04 to } \\
1.84)\end{array}$ & 580 & $\begin{array}{c}1.38(1.02 \text { to } \\
1.86)\end{array}$ & 292 & $\begin{array}{c}0.97 \text { ( } 0.67 \text { to } \\
1.41)\end{array}$ & 264 & $\begin{array}{c}0.95 \text { (0.63 to } \\
1.42)\end{array}$ \\
\hline
\end{tabular}

*Adjusted for sex, birth weight, gestational age, mode of delivery, respiratory diagnoses as newborn, maternal age at delivery, parity, family situation, maternal exposure to antibiotics in fetal life, age as analysis time scale, and parity included as interaction term with age. Individuals with missing information on included variables excluded.

†All families discordant on asthma are included in analyses, but only those also discordant on exposure contribute to estimates in table, therefore number of cases is number of families with siblings discordant for both antibiotic exposure and asthma. 
Table 8| Hazard ratios (HR) and 95\% confidence intervals for asthma from age 2 in relation to exposure to any, airway, and urinary tract/skin antibiotics in first year of life in full cohort of children

\begin{tabular}{|c|c|c|}
\hline & Crude $^{\star}$ HR $(95 \% \mathrm{Cl})$ & Adjusted†‡ HR $(95 \% \mathrm{Cl})$ \\
\hline Any & $1.18(1.11$ to 1.26$)$ & 1.23 (1.15 to 1.32$)$ \\
\hline Airway & 1.19 (1.12 to 1.27$)$ & 1.24 (1.16 to 1.33$)$ \\
\hline Urinary tract/skin & 1.25 (1.08 to 1.43$)$ & 1.24 (1.08 to 1.44$)$ \\
\hline
\end{tabular}

*655 137 person years and 4915 events.

†612 270 person years and 4601 events.

$\ddagger$ Adjusted for sex, birth weight, gestational age, mode of delivery, respiratory diagnoses as newborn, maternal age at delivery, parity, family situation, maternal exposure to antibiotics in fetal life, mother's country of birth, parental education, and age as analysis time scale. Individuals with missing information on included variables excluded. 
Table $9 \mid$ Hazard ratios (HR) and 95\% confidence intervals for asthma from age 2 in relation to exposure to any, airway, and urinary tract/skin antibiotics in first year of life for children with siblings

\begin{tabular}{|c|c|c|c|c|}
\hline & \multicolumn{2}{|c|}{ Crude } & \multicolumn{2}{|c|}{ Adjusted $^{*}$} \\
\hline & Casest & HR $(95 \% \mathrm{Cl})$ & Cases† & HR (95\% Cl) \\
\hline Any & 568 & $0.93(0.70$ to 1.23$)$ & 523 & 0.90 (0.66 to 1.23$)$ \\
\hline Airway & 550 & $0.98(0.74$ to 1.30$)$ & 505 & $1.01(0.75$ to 1.38$)$ \\
\hline Urinary tract/skin & 120 & 0.99 (0.56 to 1.74$)$ & 107 & $0.63(0.32$ to 1.25$)$ \\
\hline
\end{tabular}

*Adjusted for sex, birth weight, gestational age, mode of delivery, respiratory diagnoses as newborn, maternal age at delivery, parity, family situation, maternal exposure to antibiotics in fetal life, age as analysis time scale, and parity included as interaction term with age. Individuals with missing information on included variables excluded

†All families discordant on asthma are included in analyses, but only those also discordant on exposure contribute to estimates in table, therefore number of cases is number of families with siblings discordant for both antibiotic exposure and asthma. 


\section{Figures}

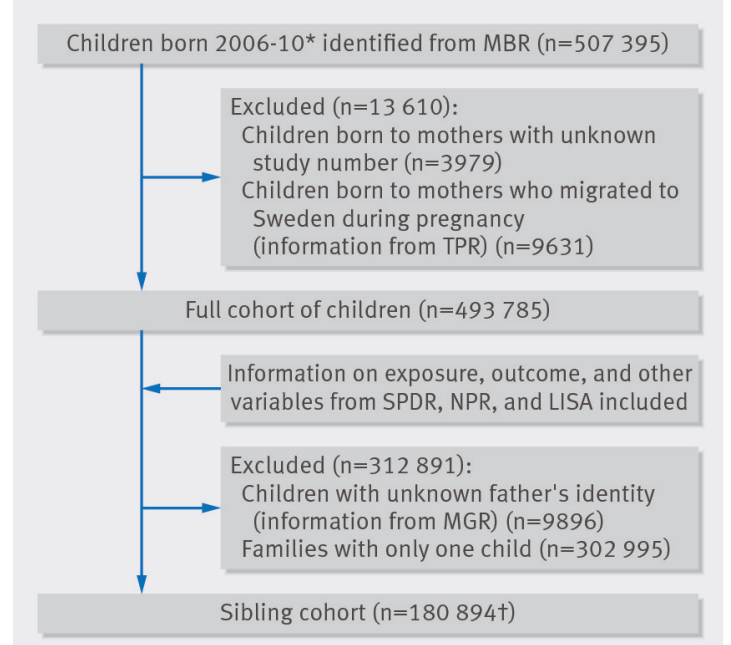

Fig 1 Final study populations for cohort and sibling control analyses. *Estimated first start of pregnancy 1 July 2005 ; first child born on 8 January 2006. $† 93 \%$ of families had two children; 7\% of families had three to five children; 12364 were twins and 267 were triplets. Registers at National Board of Health and Welfare: MBR=Medical Birth Register; SPDR=Swedish Prescribed Drug Register; NPR=National Patient Register. Registers at Statistics Sweden: TPR=Total Population Register; LISA=Longitudinal integration database for health insurance and labour market studies; MGR=Multi-Generation Register 



Fig 2 Adjusted hazard ratio and 95\% confidence interval for asthma in relation to time (in years) since first exposure to various antibiotics in childhood. Hazard ratio adjusted for attained age, sex, birth weight, gestational age, mode of delivery, respiratory diagnoses as newborn, maternal age at delivery, parity, family situation, mother's country of birth, and parental education. UTI=urinary tract infection 